\title{
Inhibitory Effects of Cyclopiazonic Acid on the Spike After-Hyperpolarization in Rat Sympathetic Neurons
}

\author{
Yasunori Ishii $\#$, Tomoyuki Kawai and Minoru Watanabe* \\ Department of Chemical Pharmacology, Faculty of Pharmaceutical Sciences, Nagoya City University, \\ Tanabe-dohri 3-1, Mizuho-ku, Nagoya 467, Japan \\ Received January 13, 1992 Accepted February 5, 1992
}

\begin{abstract}
Cyclopiazonic acid (CPA), a novel specific inhibitor of $\mathrm{Ca}^{2+}$-ATPase in muscle sarcoplasmic reticulum, shortened the $\mathrm{Ca}^{2+}$-dependent after-hyperpolarization (AHP) following a spike in the rat superior cervical ganglion. This inhibitory effect was reversible and dependent on concentrations between 1 and $5 \mu \mathrm{M}$. The AHP in the presence of $5 \mu \mathrm{M}$ CPA was not depressed further by ryanodine, nor was it affected by repetitive stimulation. These results suggest that CPA inhibits the intracellular $\mathrm{Ca}^{2+}$ release, probably due to the depletion of $\mathrm{Ca}^{2+}$ stores induced by inhibition of the ATP-dependent $\mathrm{Ca}^{2+}$ pump.
\end{abstract}

During neuronal excitation, the cytoplasmic $\mathrm{Ca}^{2+}$ concentration is increased by $\mathrm{Ca}^{2+}$ entry through channels in the plasma membrane and/or $\mathrm{Ca}^{2+}$ release from intracellular stores. The functional $\mathrm{Ca}^{2+}$ release from store sites induced by membrane depolarizations or by an application of caffeine has been indicated by $\mathrm{Ca}^{2+}$ transients in fura-2-loaded cells $(1,2)$ or by detecting an activation of $\mathrm{Ca}^{2+}$-activated potassium conductance $(3,4)$, e.g., the longlasting after-hyperpolarization following a spike in sympathetic neurons (5). Certain organelles accumulate $\mathrm{Ca}^{2+}$ in an ATP-dependent fashion and play a significant role in intracellular $\mathrm{Ca}^{2+}$ buffering (6). The aim of the present study was to examine whether the organelles, which release $\mathrm{Ca}^{2+}$ to cytoplasm in response to physiological depolarization (action potentials), accumulates the $\mathrm{Ca}^{2+}$ via

\footnotetext{
\#Present address: Biology Section, Shirakawa Laboratory, Nippon Roussel, 103-1 Ushishimizu, Shirakawa, Fukushima 961, Japan.

* To whom correspondence should be addressed.
}

$\mathrm{Ca}^{2+}$-ATPase in neuronal cells. For this purpose, we examined the effects of cyclopiazonic acid, a mycotoxin produced by certain fungi of the Aspergillus and Penicillium genera, on the spike after-hyperpolarization in the rat superior cervical ganglion, since this agent was recently found to specifically inhibit the $\mathrm{Ca}^{2+}$-ATPase and $\mathrm{Ca}^{2+}$-transport activities of muscle sarcoplasmic reticulum $(\mathrm{SR})(7,8)$, without significant effects on the hydrolysis of ATP by the $\mathrm{Na}^{+} / \mathrm{K}^{+}$-ATPase, $\mathrm{H}^{+} / \mathrm{K}^{+}$-ATPase, mitochondrial $\mathrm{F}_{1}$-ATPase, erythrocyte $\mathrm{Ca}^{2+}$-ATPase, and $\mathrm{Mg}^{2+}$-ATPase of plasma membranes (9).

Superior cervical ganglia were excised from male Wistar rats weighing $250-300 \mathrm{~g}$. The isolated ganglion was placed in an organ bath and superfused with saline containing, 137.9 $\mathrm{mM} \mathrm{NaCl}, 4.0 \mathrm{mM} \mathrm{KCl}, 2.0 \mathrm{mM} \mathrm{CaCl}_{2}, 0.5$ $\mathrm{mM} \quad \mathrm{MgCl}_{2}, \quad 12.0 \mathrm{mM} \quad \mathrm{NaHCO}_{3}, \quad 1.0 \mathrm{mM}$ $\mathrm{KH}_{2} \mathrm{PO}_{4}$, and $11.1 \mathrm{mM}$ glucose. The solution was gassed with $5 \% \mathrm{CO}_{2}$ and $95 \% \mathrm{O}_{2}$ and was maintained at $\mathrm{pH}$ 7.4. Experiments were carried out at $35^{\circ} \mathrm{C}$. Intracellular recordings were made with glass micro-electrodes containing 
$3 \mathrm{M} \mathrm{KCl}$ and having a resistance between 40 and $60 \mathrm{Mohm}$. Action potentials were evoked by an anodal current of 4-msec duration across the cell membrane. The current was applied through the recording electrode by use of an active bridge circuit. Data were collected from cells having resting membrane potentials more negative than $-50 \mathrm{mV}$ and action potentials greater than $65 \mathrm{mV}$ in peak amplitude. Data acquisition to and analysis on a computer (IBM-PC/AT or compatible) was performed as described previously $(5,10)$.

Drugs used were: caffeine anhydride, ryanodine (Wako Pure Chemicals); and cyclopiazonic acid, apamin (Sigma). Cyclopiazonic acid was dissolved in $100 \%$ dimethyl sulfoxide for stock solutions $(10 \mathrm{mM})$ and diluted with the physiological saline to final concentrations. The stock solution was stored at $-20^{\circ} \mathrm{C}$ up to 1 week. The solvent alone did not cause any changes in membrane potentials. Data are expressed as means $\pm \mathrm{S}$.E.

The action potential was followed by a long-lasting after-hyperpolarization (AHP), which is linked to $\mathrm{Ca}^{2+}$-activated $\mathrm{K}^{+}$conductance. As shown in the inset of Fig. 1A (also in Fig. 2A), the AHP had a fast negative peak (filled triangle) and a slowly-occurring second peak (open triangle). The latter was accentuated by caffeine and was abolished by ryanodine (data not shown, see ref. 5); these agents are known to accelerate and inhibit the intracellular $\mathrm{Ca}^{2+}$ release, respectively. Therefore, this biphasic wave-form of the AHP is suggested to be attributable to two different mechanisms for an increase in intracellular $\mathrm{Ca}^{2+}$ concentration, the $\mathrm{Ca}^{2+}$ influx from extracellular space via voltage-dependent $\mathrm{Ca}^{2+}$ channels during an action potential and the intracellular $\mathrm{Ca}^{2+}$ release from caffeine-sensitive store sites via the mechanism of $\mathrm{Ca}^{2+}$-induced $\mathrm{Ca}^{2+}$ release (5). Because of the biphasic nature, changes in the AHP were assessed by the area of membrane potential more negative than the resting membrane potential.

Figure $1 \mathrm{~A}$ shows the typical time course of the effects of $5 \mu \mathrm{M}$ cyclopiazonic acid (CPA) on the area of AHP when the stimulation was applied at $0.033 \mathrm{~Hz}$. After an application of CPA, the area of AHP was gradually and dramatically reduced and reached a steady level within $5 \mathrm{~min}$. This inhibition was recovered by washing the tissue for $10 \mathrm{~min}$. The slowlyoccurring second peak of the AHP was not observed in the presence of CPA (Fig. 1A, inset). The $50 \%$ duration of the AHP, which was measured at $50 \%$ amplitude of the fast peak, was significantly decreased by $5 \mu \mathrm{M}$ CPA from $174.5 \pm 15.8 \mathrm{msec}$ to $35.6 \pm 8.3$ msec $(n=5)$. The amplitude of the fast peak was not altered $(14.7 \pm 0.6 \mathrm{mV}$ in the control and $14.5 \pm 0.5 \mathrm{mV}$ in the presence of CPA, $n=5$ ). When the frequency of stimulation was increased to $1 \mathrm{~Hz}$ (triangle in Fig. 1A), the area of AHP was reduced nearly to the value obtained in the presence of CPA, due to the abolition of the second peak of the AHP in agreement with previous findings (10). This reduction in the area of AHP was no longer observed in the presence of CPA.

Next, we examined whether the inhibitory effect of CPA on the AHP developed in a use-dependent manner (Fig. 1B). In this cell, the inhibition of the AHP by CPA was completely achieved within $2 \mathrm{~min}$. After washing the tissue, CPA was administered again but simultaneously the stimulation of the cell was discontinued for $3 \mathrm{~min}$. Maximal effects of CPA were already observed when the stimulation was resumed. Since the rest period of stimulation by itself had no effects on the AHP, the results suggest no apparent use-dependency in the development of the inhibition of AHP by CPA. Similar results were obtained in 3 other cells.

The resting membrane potential and the action potential were not affected by $5 \mu \mathrm{M}$ CPA. Averaged values of the peak amplitude and the duration of action potentials were 72.2 $\pm 3.1 \mathrm{mV}$ and $1.2 \pm 0.1 \mathrm{msec}$ in the control $(\mathbf{n}=5)$ and $73.3 \pm 3.5 \mathrm{mV}$ and $1.2 \pm 0.1$ msec in the presence of CPA $(n=5)$, respectively.

Figure $2 \mathrm{~A}$ shows the effects of ryanodine and apamin on the AHP in the presence of CPA. This series of experiments was per- 


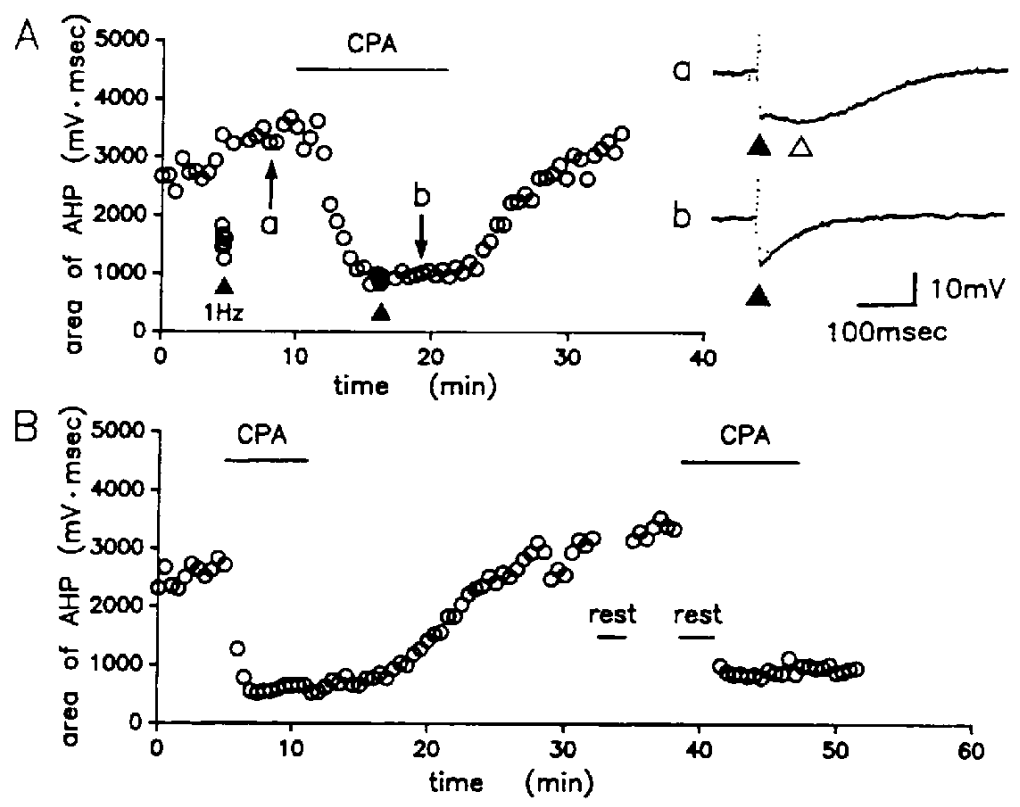

Fig. 1. Effects of cyclopiazonic acid (CPA) on after-hyperpolarization (AHP). A: Time course of the area of AHP. Triangles denote repetitive stimulation at $1 \mathrm{~Hz}$ for $20 \mathrm{sec}$. CPA $(5 \mu \mathrm{M})$ was applied as indicated by the horizontal bar. Right hand panels (inset) show typical records of the AHP in the absence (a) and presence (b) of CPA. Filled and open triangles indicate the fast peak and the slowly-occurring second peak of the AHP as described in the text. Action potentials are not fully drawn. B: Effects of rest period of stimulation (lower horizontal bars) on the development of the inhibitory action of CPA. Typical observation of 4 experiments.

formed in the presence of $1 \mathrm{mM}$ caffeine in order to facilitate the intracellular $\mathrm{Ca}^{2+}$ release. CPA $(5 \mu \mathrm{M})$ reduced the area of AHP to a similar extent to that seen in Fig. 1. The reduction of AHP by repetitive stimulation at $1 \mathrm{~Hz}$ also disappeared in the presence of CPA. Slight or no further substantial reduction of the area of AHP was observed by $5 \mu \mathrm{M}$ ryanodine, but the residual area was nearly abolished by $0.1 \mu \mathrm{M}$ apamin. The configuration of the AHP in the presence of CPA was not altered by ryanodine, but significantly shortened by apamin. Similar results were obtained in 3 other cells. Since the concentration of ryanodine is sufficient to cause its maximum effect (5), these results indicate that CPA inhibits the same component of the AHP as ryanodine does, and it inhibits a part of the apamin-sensitive component of the AHP.

The inhibitory effects of CPA on the area of
AHP was dependent on concentrations between 1 and $5 \mu \mathrm{M}$ (Fig. 2B). The concentration for a half inhibition $\left(\mathrm{IC}_{50}\right)$ was approximately $2 \mu \mathrm{M}$. The maximal inhibition caused by CPA was the same magnitude as that caused by $5 \mu \mathrm{M}$ ryanodine alone.

The present study demonstrates that CPA inhibits the AHP following the spike in the rat sympathetic neurons. These effects of CPA had several similarities to that of ryanodine reported previously in the same tissue (5). First, the inhibitory effect was selective to the AHP, and the configuration of the action potential was not affected. Second, both agents reduced the duration of AHP and abolished the slowlyoccurring second peak of the AHP which was accentuated by caffeine. Third, the maximal effect on the AHP was a partial inhibition of the apamin-sensitive component, and those caused by CPA and ryanodine were similar in 

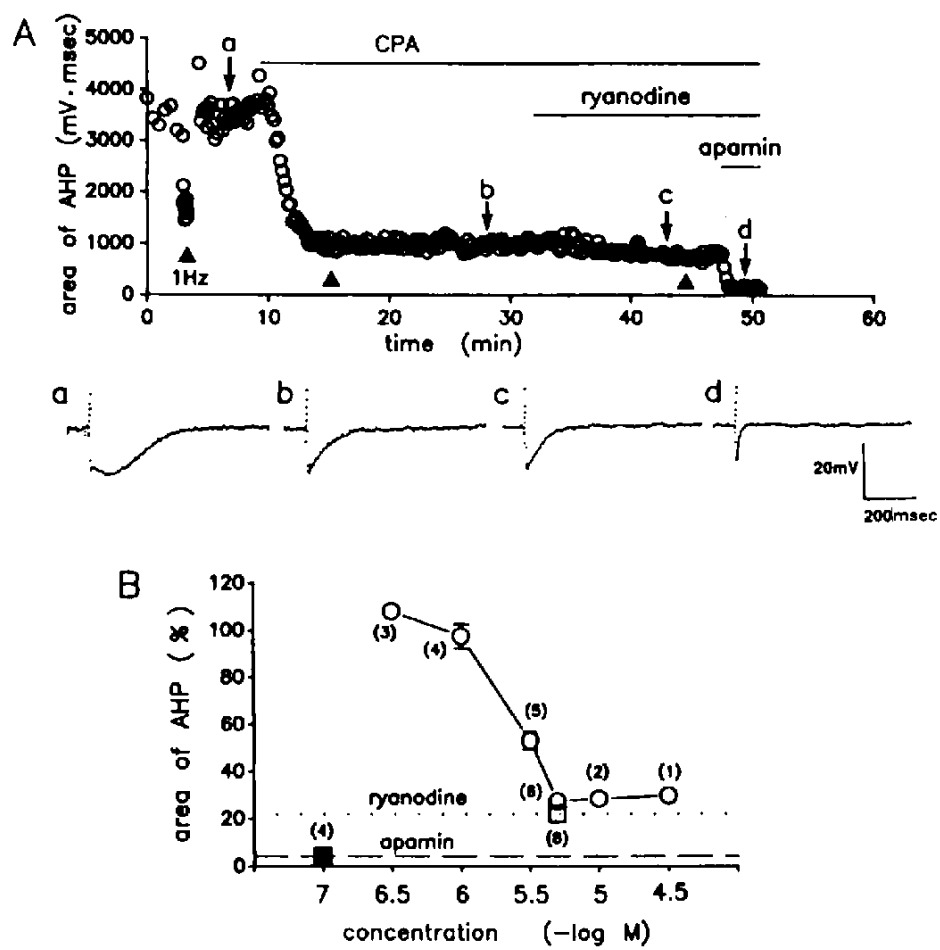

Fig. 2. Effects of cyclopiazonic acid (CPA), ryanodine, and apamin on the after-hyperpolarization (AHP) in the presence of $1 \mathrm{mM}$ caffeine. A: Time course of the area of AHP. CPA $(5 \mu \mathrm{M})$, ryanodine $(5 \mu \mathrm{M})$ and apamin $(0.1 \mu \mathrm{M})$ were applied as indicated in the horizontal bars. Triangles denote repetitive stimulation at $1 \mathrm{~Hz}$ for $20 \mathrm{sec}$. Bottom panels ( $a, b, c$, and $\mathrm{d}$ ) show typical records of the AHP at the indicated time. B: Dose-dependent effects of CPA (circles) on the relative area of AHP. Dashed lines show the mean value of the area of AHP in the presence of $5 \mu \mathrm{M}$ ryanodine (open square) and in the presence of $0.1 \mu \mathrm{M}$ apamin (filled square), respectively. The number of experiments is indicated in parentheses. The area of AHP before an application of drugs was taken as $100 \%$. Symbols represent mean values and S.E.M. are within the symbols.

magnitude. Fourth, CPA as well as ryanodine abolished the component of the AHP which was reduced during repetitive stimulation at $1 \mathrm{~Hz}$. It was reported that the depression of the AHP during repetitive stimulations is attributable to a decrease in intracellular $\mathrm{Ca}^{2+}$ release due to the depletion of $\mathrm{Ca}^{2+}$ stores $(10)$. Fifth, the effects of both agents developed gradually and reached a steady-state within 5 min. This time-course was slower than that of the direct effects of apamin on $\mathrm{Ca}^{2+}$-activated $\mathrm{K}^{+}$channels (within $1 \mathrm{~min}$, Fig. $2 \mathrm{~A}$ ) in our perfusion system. Finally, the voltage-dependent $\mathrm{Ca}^{2+}$ currents were not affected by CPA
(M. Watanabe, M. Suzuki and Y. Imaizumi, unpublished observations) and ryanodine (5). The inhibitory effect of CPA on the AHP was easily removed by washing, while the recovery from the effects of ryanodine were observed after washing for more than $1 \mathrm{hr}$ (5). This is the only observable difference in features between CPA and ryanodine. These results suggest that CPA and ryanodine have a common mechanism for suppressing the AHP, inhibition of the intracellular $\mathrm{Ca}^{2+}$ release from store sites in rat sympathetic neurons. Lack of additional effects induced by the combination of CPA and ryanodine even in the presence of 
caffeine supports this suggestion and excludes the possibility that CPA directly blocks a part of the $\mathrm{Ca}^{2+}$-activated $\mathrm{K}^{+}$channels. Ryanodine locks the $\mathrm{Ca}^{2+}$-release channel to the open sub-state and depletes the $\mathrm{Ca}^{2+}$ stores $(11,12)$. Therefore, CPA is readily expected to deplete $\mathrm{Ca}^{2+}$ stores by inhibition of $\mathrm{Ca}^{2+}$. ATPase and consequently to produce effects on the AHP apparently similar to those of ryanodine in sympathetic neurons.

The precise mechanism of action of CPA remains unclear in neurons. It is reported that CPA specifically inhibits the $\mathrm{Ca}^{2+}$-ATPase of muscle SR without affecting other ATPases involved in ion transport across the membrane (9). In nerve cells and synaptosomes, putative $\mathrm{Ca}^{2+}$ stores, including the endoplasmic reticulum and "calciosomes" (13), have been found to accumulate $\mathrm{Ca}^{2+}$ in an ATP-dependent fashion very similar, if not identical, to muscle SR (6). A study using a hybridization probe corresponding to part of the ATP binding site of the $\mathrm{SR} \mathrm{Ca}^{2+}$-ATPase suggests that the $\mathrm{Ca}^{2+}$-ATPase with nucleotide sequence closely related to the slow-twitch muscle SR $\mathrm{Ca}^{2+}$. ATPase is expressed in the brain (14). It is suggested that the inhibition of ATPase activity by CPA may be related to the inhibition of the conformational changes associated with ATP hydrolysis and $\mathrm{Ca}^{2+}$ transport (9). In the present study, the $\mathrm{IC}_{50}$ for $\mathrm{CPA}$ for inhibiting the AHP is slightly higher than that for inhibiting SR $\mathrm{Ca}^{2+}$-ATPase, while the maximal inhibition of AHP at $5 \mu \mathrm{M}$ is well-consistent with such biochemical measurements (7, 9, 15). Therefore, it is very likely that CPA inhibits the ATP-dependent $\mathrm{Ca}^{2+}$ pump of intracellular store sites in sympathetic neurons. Since a use-dependent effect of CPA was not observed in the present study, the possibility of direct inhibition of $\mathrm{Ca}^{2+}$ release channels can not be ruled out. Further studies will be required.

Finally, the present study supports the functional intracellular $\mathrm{Ca}^{2+}$ release contributing to generation of long-lasting AHP in sympathetic neurons. CPA may be a useful pharmacological tool to study the function of caffeine- sensitive $\mathrm{Ca}^{2+}$ stores for intracellular $\mathrm{Ca}^{2+}$ buffering in neuronal tissues as well as in muscles.

\section{REFERENCES}

1 Lipscombe, D., Madison, D.V., Poenie, M., Reuter, H., Tsien, R.W. and Tsien, R.Y.: Imaging of cytosolic $\mathrm{Ca}^{2+}$ transients arising from $\mathrm{Ca}^{2+}$ stores and $\mathrm{Ca}^{2+}$ channels in sympathetic neurons. Neuron 1, 355-365 (1988)

2 Thayer, S.A., Hirning, L.D. and Miller, R.J.: The role of caffeine-sensitive calcium stores in the regulation of the intracellular free calcium concentration in rat sympathetic neurons in vitro. Mol. Pharmacol. 34, 664-673 (1988)

3 Kuba, K.: Release of calcium ions linked to the activation of potassium conductance in a caffeinetreated sympathetic neurone. J. Physiol. (Lond.) 298, $251-269$ (1980)

4 Akaike, N. and Sadoshima, J.: Caffeine affects different ionic currents in the bull-frog sympathetic neurone. J. Physiol. (Lond.) 412, 221 - 244 (1989)

5 Kawai, T. and Watanabe, M.: Effects of ryanodine on the spike after-hyperpolarization in sympathetic neurones of the rat superior cervical ganglion. Pflugers Arch. 413, $470-475$ (1989)

6 Blaustein, M.P.: Calcium transport and buffering in neurons. Trends Neurosci. 11, 438-443 (1988)

7 Goeger, D.E., Riley, R.T., Domer, J.W. and Cole, R.J.: Cyclopiazonic acid inhibition of the $\mathrm{Ca}^{2+}$-transport ATPase in rat skeletal muscle sarcoplasmic reticulum vesicles. Biochem. Pharmacol. 37, 978-981 (1988)

8 Goeger, D.E. and Riley, R.T.: Interaction of cyclopiazonic acid with rat skeletal muscle sarcoplasmic reticulum vesicles. Biochem. Pharmacol. 38, 3995- 4003 (1989)

9 Seider, N.W., Jona, I., Vegh, M. and Martonosi, A.: Cyclopiazonic acid is a specific inhibitor of $\mathrm{Ca}^{2+}$-ATPase of sarcoplasmic reticulum. J. Biol. Chem. 264, 17816-17823 (1989)

10 Kawai, T. and Watanabe, M.: Ryanodine suppresses the frequency-dependent component of the spike after-hyperpolarization in the rat superior cervical ganglion. Japan. J. Pharmacol. 55, 367374 (1991)

11 Ashley, R.H.: Activation and conductance properties of ryanodine-sensitive calcium channels from brain microsomal membranes incorporated into planer lipid bilayers. J. Membr. Biol. 111, 179189 (1989)

12 Fill, M. and Coronado, R.: Ryanodine receptor channel of sarcoplasmic reticulum. Trends Neuro- 
sci. 11, $453-457$ (1988)

13 Rossier, M.F. and Putney, J.W.: The identity of the calcium-storing, inositol 1,4,5-trisphosphatesensitive organelle in non-muscle cells: calciosome, endoplasmic reticulum...or both? Trends Neurosci. 14, 310-314 (1991)

14 Gunteski-Hamblin, A.-M., Greeb, J. and Shull, G.E.: A novel $\mathrm{Ca}^{2+}$ pump expressed in brain, kidney, and stomach is encoded by an alternative transcript of the slow-twitch muscle sarcoplasmic reticulum Ca-ATPase gene. J. Biol. Chem. 263, $15032-15040$ (1988)

15 Kurebayashi, N. and Ogawa, Y.: Discrimination of $\mathrm{Ca}^{2+}$-ATPase activity of the sarcoplasmic reticulum from actomyosin-type ATPase activity of myofibrils in skinned mammalian skeletal muscle fibres: distinct effects of cyclopiazonic acid on the two ATPase activities. J. Muscle Res. Cell Motil. 12, 355-365 (1991) 